\title{
Conservative Treatment of Avulsion Injuries of the Lesser Trochanter in Adolescent Athletes
}

\author{
Alexander Volpi ${ }^{1}$, Chelsea Matzko ${ }^{1}$, Daniel Feghhi ${ }^{1}$, Travis Matheney ${ }^{2}$, Srino Bharam ${ }^{1}$ \\ 1. Orthopaedic Surgery, Lenox Hill Hospital, New York, USA 2. Orthopaedic Surgery, Boston Children's Hospital, \\ Boston, USA
}

Corresponding author: Alexander Volpi, alex.volpi20@gmail.com

\begin{abstract}
Background: Avulsion injuries of the lesser trochanter apophysis are relatively uncommon injuries and there have been no peer-reviewed case series dedicated to the evaluation and treatment of this injury. The purpose of this study is to characterize avulsion injuries of the lesser trochanter apophysis, review treatment protocols, and time to return to sport.
\end{abstract}

Methods: We reviewed 30 confirmed avulsion fractures of the lesser trochanter. Clinical data were reviewed to evaluate treatment protocols, duration, and time to return to sport. Radiographs were reviewed to confirm lesser trochanter avulsion and fracture displacement.

Results: There were 26 males and 4 females, with the average age at the time of injury being 14.2 years. Treatment modalities consisted of protective weight-bearing, discontinuation of the patient's sport in all cases, and formal physical therapy in 18 cases. The average treatment duration was 30.7 days. The mean follow-up time was 102 days. The radiographic assessment demonstrated an average fracture displacement of $5.1 \mathrm{~mm}$. The average return to sport was 11 weeks.

Conclusion: This is the first large case series studying avulsion injuries of the lesser trochanter. We have shown that these athletes can be managed non-surgically and can successfully return back to sport within three months.

Review began 05/27/2021 Review ended 06/03/2021 Published 06/14/2021

() Copyright 2021 Volpi et al. This is an open access article distributed under the terms of the Creative Commons Attribution License CC-BY 4.0., which permits unrestricted use, distribution, and reproduction in any medium, provided the original author and source are credited.
Categories: Pediatrics, Orthopedics

Keywords: pelvic avulsion injuries, lesser trochanter avulsion injuries, pediatric orthopaedics, pediatric sports medicine, adolescent sports injuries

\section{Introduction}

Pelvic avulsion injuries are well described in the literature, and athletic injuries to the hip and groin can comprise up to 1 in 10 patient visits to sports medicine clinics [1-6]. Six common sites of pelvic avulsion injuries have been described with injuries to the ischial tuberosity, anterior inferior, and superior iliac spines occurring most commonly [2]. Avulsion injuries of the lesser trochanter apophysis are relatively uncommon but predominantly occur in adolescent male athletes [1,2,6-9]. It has been reported in the literature that isolated lesser trochanter avulsion fractures account for less than $1 \%$ of a sports medicine physician's practice $[8,10]$.

Avulsion fractures of the lesser trochanter occur typically during sport due to strong muscle contraction of the iliopsoas on an apophysis with an open growth plate. The cartilaginous growth plate may be at increased risk of trauma compared to the musculotendinous units $[2,7,11]$. The primary mechanism of acute injury is a sudden forceful eccentric contraction of the iliopsoas in an attempt to accelerate or decelerate the body, typically occurring during athletic activity [12]. An alternative mechanism of injury is a sudden excessive passive muscle stretching [7].

Given the relatively rare occurrence of this injury, there are a limited number of case studies describing this topic, and treatment methods and outcomes have been varied in the reported literature [7-10,13-15]. Historically, pelvic avulsion fractures have been treated nonoperatively most commonly with analgesics and physical rehabilitation $[13,16]$. However, some controversy exists whether operative treatment is beneficial in these types of injuries, either as primary treatment or secondary treatment after failed conservative management [17-19].

There are limited reports in the literature regarding sport-specific outcomes in lesser trochanter avulsion fractures. As we see more adolescents playing highly competitive sports, early and correct diagnosis is pivotal for a successful return to sports. The purpose of this study is to characterize avulsion injuries of the lesser trochanter apophysis, review treatment protocols, and correlate with a time to return to sport. We hypothesized that patients with lesser trochanter avulsion fractures can be treated with conservative management with a successful return to sport and function. 


\section{Materials And Methods}

A retrospective review was performed at a Level 1 Pediatric Trauma Center between 2007 and 2017. Institutional Review Board approval was obtained to conduct this retrospective review, and a database search within the electronic medical record was performed using keywords "lesser trochanter" and "avulsion injury.” Using these criteria, the search returned 138 patients between ages 2 and 18. Following a further review of radiographs and clinical documentation, 30 confirmed acute avulsion fractures of the lesser trochanter were included in this case series. Chronic or non-athletic injuries were excluded. Clinical data were reviewed retrospectively to determine demographic data, sport involved, weight-bearing status, therapy protocol, duration of treatment, and time to return to sport. Return to the sport was defined as when the patient returned to practice or gameplay without limitation or disability. Radiographs of all patients were reviewed. The amount of fracture displacement was measured on the AP pelvis and/or hip radiograph used to determine the type of avulsion fracture, and evaluate for concomitant injuries. Avulsion fractures were classified as type 1 if non-displaced, type 2 if there was a displacement of less than or equal to $2 \mathrm{~cm}$, type 3 if displacement was greater than $2 \mathrm{~cm}$, and type 4 if there was a symptomatic nonunion or painful exostosis $[1,20]$. A Pearson's product-moment correlation coefficient was computed to assess the relationship between the following variables: BMI, age, weight-bearing status, sport involved, duration of treatment, radiologic displacement, and return to sport time were all statistically analyzed for correlation.

\section{Results}

During the study period, avulsion fractures of the lesser trochanter were found in 30 patients (26 male, 4 female). The average age at the time of injury was 14.2 years (range: 7.7-17.5 years) with an average body mass index (BMI) of 21.1 (range: 16.9- 29.7). The mean follow-up time was 102 days. The injuries were traumatic and sustained during sports in all 30 patients. The sports patients were involved in prior to the injury included hockey, soccer, basketball, baseball, track and field, football, and cheerleading (Table 1).

\begin{tabular}{|c|c|c|c|c|c|c|c|c|c|c|}
\hline $\begin{array}{l}\text { Patient } \\
\text { number }\end{array}$ & Laterality & $\begin{array}{l}\text { Age at } \\
\text { injury }\end{array}$ & BMI & Sport involved & $\begin{array}{l}\text { Displacement } \\
(\mathrm{mm})\end{array}$ & Classification & $\begin{array}{l}\text { Weight-bearing } \\
\text { status }\end{array}$ & $\begin{array}{l}\text { Treatment } \\
\text { duration }\end{array}$ & Activities/PT/rehab & $\begin{array}{l}\text { Return to sport } \\
\text { time (days) }\end{array}$ \\
\hline 1 & Left & 12.4 & 29.7 & Football & 4 & 2 & PWB & 28 & $n / a$ & 75 \\
\hline 2 & Left & 17.5 & 21.1 & Baseball & 10 & 2 & TTWB & 21 & Jogging, baseball & 99 \\
\hline 3 & Right & 16.5 & 20.9 & $\begin{array}{l}\text { Distance } \\
\text { runner }\end{array}$ & 5 & 2 & PWB & 28 & $\mathrm{n} / \mathrm{a}$ & 80 \\
\hline 4 & Right & 15.0 & 19.9 & $\begin{array}{l}\text { Baseball, } \\
\text { basketball }\end{array}$ & 17 & 2 & WBAT & 60 & PT & 75 \\
\hline 5 & Right & 12.0 & 17.7 & Hockey & 6 & 2 & WBAT & 21 & PT, no hockey & 35 \\
\hline 6 & Right & 16.0 & 18.4 & Hockey & 15 & 2 & PWB & 21 & $\begin{array}{l}\text { No stretching, PT, WBAT, gradual } \\
\text { return to sport }\end{array}$ & 186 \\
\hline 7 & Right & 16.6 & 18.9 & Soccer & 7 & 2 & WBAT & 28 & PT/ROM, no soccer & 59 \\
\hline 8 & Right & 15.3 & 25.8 & Basketball & 5 & 2 & WBAT & 28 & PT, a gradual return to activity & 70 \\
\hline 9 & Left & 14.4 & 21 & Basketball & 4 & 2 & WBAT & 42 & PT, no sports $\times 6$ weeks & 80 \\
\hline 10 & Right & 14.6 & 24.7 & Cheerleading & 0 & 1 & NWB & 28 & PT, wean back to sports & 139 \\
\hline 11 & Left & 15.7 & 17.4 & Soccer & 4 & 2 & WBAT & 28 & No sport & 125 \\
\hline 12 & Right & 12.9 & 22 & Football & 5 & 2 & PWB & 35 & $\mathrm{n} / \mathrm{a}$ & 80 \\
\hline 13 & Left & 16.2 & 26.2 & Basketball & 6 & 2 & WBAT & 35 & PT, no sport & 75 \\
\hline 14 & Right & 15.2 & 20.4 & Soccer & 5 & 2 & WBAT & 35 & PT, no flexion, no sport & 74 \\
\hline 15 & Right & 13.5 & 24.2 & Hockey & 2 & 2 & TTWB & 28 & No sport, TTWB & 27 \\
\hline 16 & Right & 13.2 & 20.2 & Hockey & 5 & 2 & WBAT & 42 & No sport, WBAT w/crutches & 42 \\
\hline 17 & Left & 12.9 & 16.9 & Baseball & 6 & 2 & PWB & 21 & No sport/run, ok to bike/swim & 121 \\
\hline 18 & Right & 18.1 & 19.7 & Basketball & 4 & 2 & PWB & 21 & No sprinting/running & 42 \\
\hline 19 & Right & 13.7 & 21.9 & Soccer & 3 & 2 & WBAT & 49 & PT, no painful activity & 177 \\
\hline \multirow[t]{2}{*}{20} & Right & 12.9 & 21.0 & Soccer & 1 & 2 & WBAT & 35 & No sport & 42 \\
\hline & & & & Football, & & & & & & \\
\hline
\end{tabular}




\section{Cureus}

\begin{tabular}{|c|c|c|c|c|c|c|c|c|c|c|}
\hline 21 & Left & 15.3 & 24.6 & wrestling & 10 & 2 & WBAT & 56 & PT, no sport & 60 \\
\hline 22 & Right & 15.5 & 18.1 & Hockey & 5 & 2 & PWB & 21 & PT, no sport & 80 \\
\hline 23 & Right & 9.6 & 20.0 & Soccer, frisbee & 1 & 2 & PWB & 21 & PT, no sport & 28 \\
\hline 24 & Right & 15.3 & 22 & Soccer & 1 & 2 & WBAT & 28 & No sport & 113 \\
\hline 25 & Left & 14.0 & 21.4 & $\begin{array}{l}\text { Running, } \\
\text { soccer }\end{array}$ & 2 & 2 & WBAT & 28 & PT, no sport & 45 \\
\hline 26 & Right & 7.7 & 17.8 & Softball & 1 & 2 & NWB & 21 & PT, no sport & 25 \\
\hline 27 & Right & 13.8 & 18.5 & Hockey & 2 & 2 & PWB & 28 & PT, no sport & 79 \\
\hline 28 & Left & 13.7 & 22.8 & Soccer & 5 & 2 & WBAT & 28 & PT, no sport & 74 \\
\hline 29 & Left & 14.1 & 19.6 & Basketball & 7 & 2 & WBAT & 28 & PT, no sport & 82 \\
\hline 30 & Left & 13.0 & 21.3 & Soccer & 5 & 2 & WBAT & 28 & PT, no sport & 61 \\
\hline
\end{tabular}

\section{TABLE 1: Summary of data}

Adolescents with acute avulsion fracture of the lesser trochanter.

WBAT: weight-bearing as tolerated, PWB: partial weight-bearing, TTWB: toe-touch weight-bearing, NWB: non-weight bearing, PT: physical therapy.

All cases were treated with nonoperative treatment modalities, consisting of discontinuation of the patient's sport in all cases and formal physical therapy in $18(60 \%)$ cases. Weight-bearing status at the initial time of treatment included weight-bearing as tolerated (WBAT) in 17 cases (57\%), partial weight bearing (PWB) in 9 cases (30\%), toe-touch weight-bearing (TTWB) in 2 cases (6.67\%), and non-weight-bearing (NWB) in 2 cases (6.67\%). The average treatment duration was 30.7 days (range 21-60 days). Radiographic assessment (Figures 1 and 2) demonstrated an average fracture displacement of $5.1 \mathrm{~mm}$ (range $0-17 \mathrm{~mm}$ ).

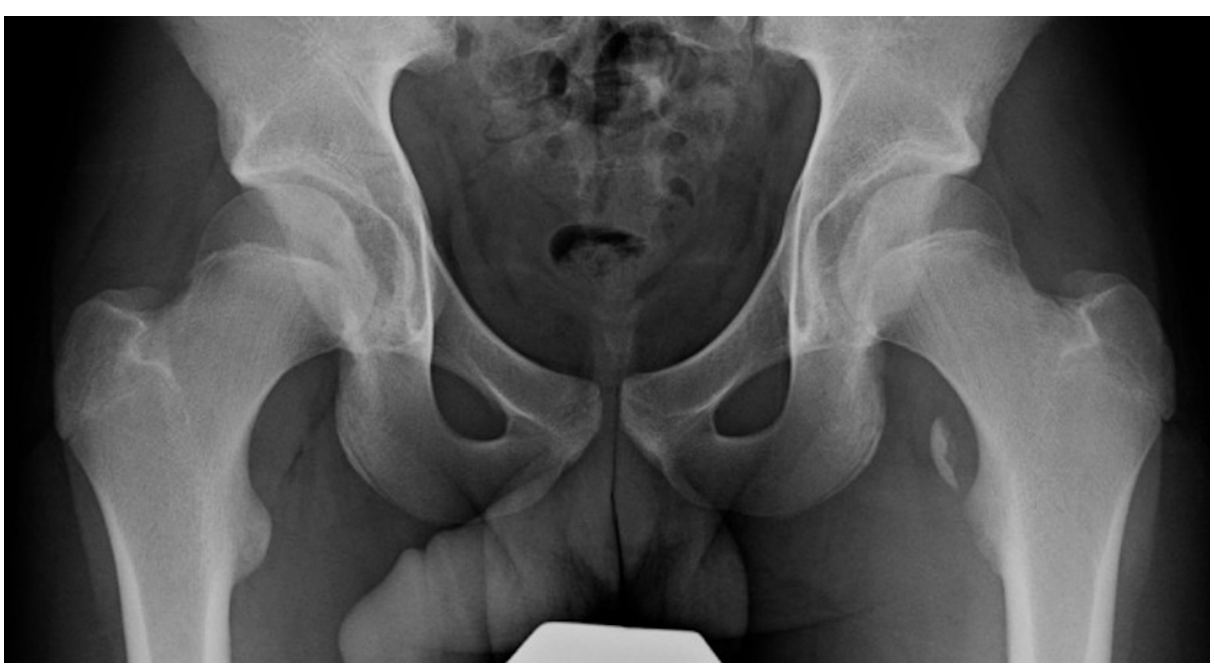

FIGURE 1: Anteroposterior pelvis radiograph of the patient with a significantly displaced avulsion fracture of a left lesser trochanter 


\section{Cureus}

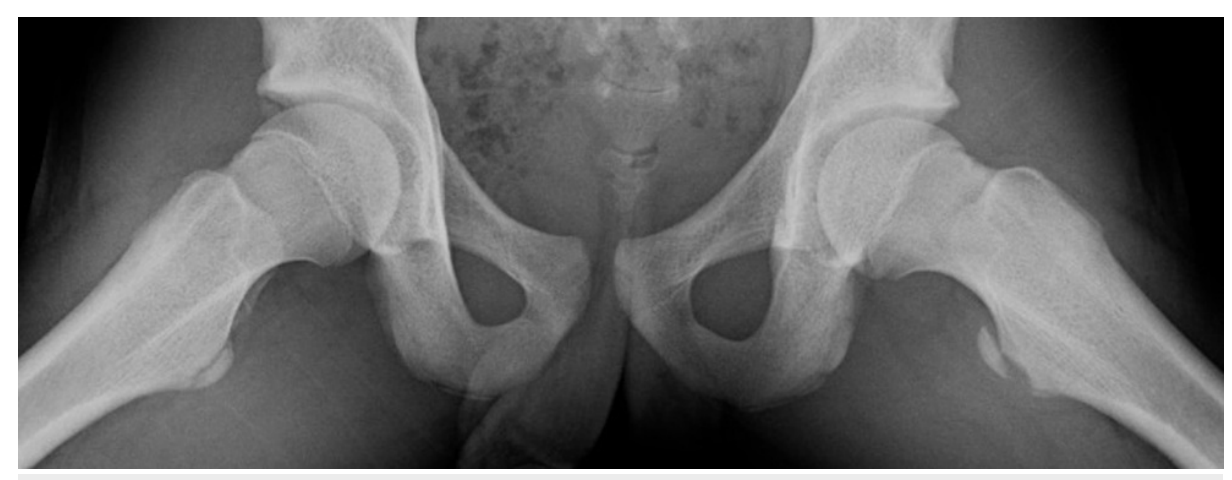

FIGURE 2: Frog-lateral radiograph demonstrating displaced avulsion fracture of the lesser trochanter

All 30 athletes returned to their sport (100\%), with the average time to return to the sport being 78.3 days (2.5 months, range). Throughout the follow-up period, there were no diagnoses of a delayed union based on the radiographic review (Figure 3).

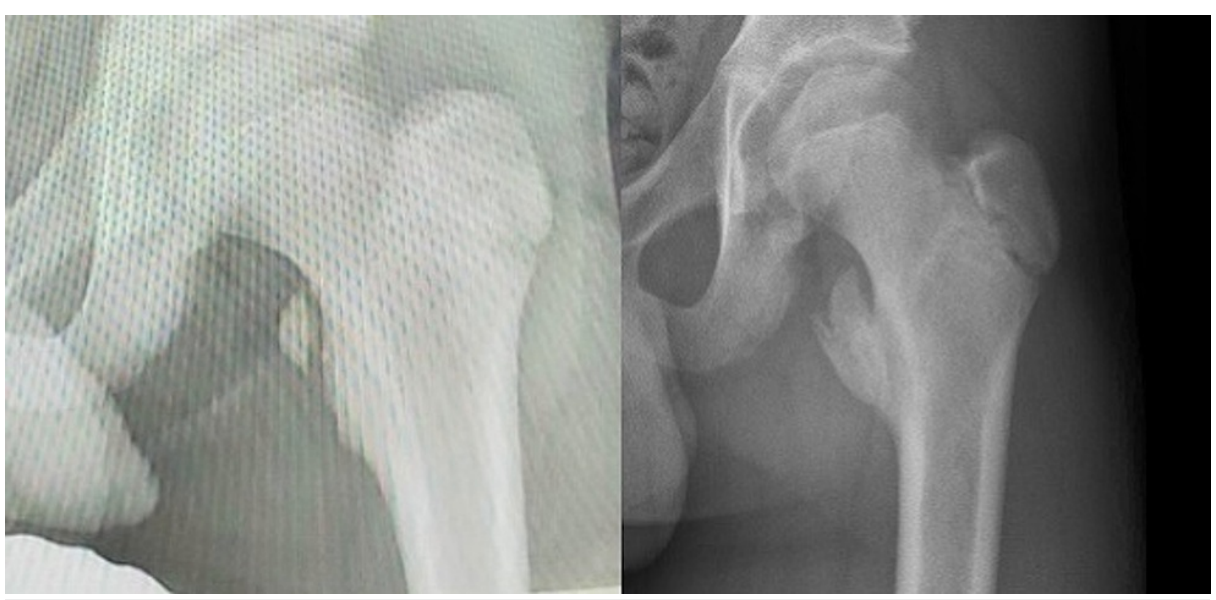

FIGURE 3: Anteroposterior pelvis radiograph of the left hip at the time of initial lesser trochanter avulsion fracture diagnosis (left) and at sixweek follow up after conservative treatment with activity modification for four weeks and weight-bearing as tolerated (right)

Of note, there was a statistically significant positive correlation between displacement and patient age $(\mathrm{r}=0.405, \mathrm{n}=30, \mathrm{p}=0.026)$. All other correlations between variables were found to be non-significant (Table 2). 


\section{Cureus}

\begin{tabular}{|c|c|c|c|c|c|c|}
\hline & 1 & 2 & 3 & 4 & 5 & 6 \\
\hline 1. Age at Injury & --- & & & & & \\
\hline 2. Return to sport time & 0.092 & --- & & & & \\
\hline 3. BMI & 0.643 & 0.834 & --- & & & \\
\hline 4. Displacement & $0.026^{\star}$ & 0.161 & 0.471 & --- & & \\
\hline 5. Sport of participation & 0.073 & 0.704 & 0.97 & 0.275 & ---- & \\
\hline 6. Duration WBS & 0.584 & 0.742 & 0.16 & 0.069 & 0.160 & $\cdots$ \\
\hline 7. WBS & 0.485 & 0.427 & 0.566 & 0.535 & 0.321 & 0.056 \\
\hline
\end{tabular}

\section{TABLE 2: Summary of correlation analysis}

Correlations between avulsion size, age, BMI, and four functional variables.

${ }^{*} \mathrm{P}$-values $<0.05$ were considered significant.

WBS: work breakdown structure.

\section{Discussion}

This is the largest case series of avulsion injuries of the lesser trochanter. Given the relatively rare occurrence of this injury, there are a limited number of case studies describing this topic, and treatment methods and outcomes have been varied in the reported literature (Table 3) [7-10,14,15]. 


\section{Cureus}

\begin{tabular}{|c|c|c|c|c|c|c|c|}
\hline Paper & $\begin{array}{l}\text { Number of } \\
\text { cases }\end{array}$ & Age & $\begin{array}{l}\text { Operative/non- } \\
\text { operative treatment }\end{array}$ & $\begin{array}{l}\text { Avulsion } \\
\text { description }\end{array}$ & Outcome & $\begin{array}{l}\text { Return to } \\
\text { sport }\end{array}$ & Complications \\
\hline $\begin{array}{l}\text { Current } \\
\text { Study }\end{array}$ & 30 & $\begin{array}{l}14.2 \\
(7.7- \\
17.5)\end{array}$ & $\begin{array}{l}\text { Non-operative, average } \\
\text { treatment duration of } \\
\text { four weeks (3-8.5 } \\
\text { weeks) }\end{array}$ & $5.1 \mathrm{~mm}(0-17 \mathrm{~mm})$ & Full recovery & $\begin{array}{l}\text { Yes } \\
\text { (30/30), the } \\
\text { average } \\
\text { time to } \\
\text { return } 11 \\
\text { weeks } \\
\text { (range 4- } \\
26.5 \\
\text { weeks) }\end{array}$ & None \\
\hline $\begin{array}{l}\text { Ruffing et } \\
\text { al. [20] }\end{array}$ & 5 & $\begin{array}{l}13- \\
15\end{array}$ & Non-operative & Types 2 and 3 & $\begin{array}{l}\text { HHS score of } 100 \text {, average } \\
4.9 \text {-year follow up }\end{array}$ & Yes (5/5) & None \\
\hline $\begin{array}{l}\text { Khemka et } \\
\text { al. [17] }\end{array}$ & 3 & $\begin{array}{l}15- \\
16\end{array}$ & $\begin{array}{l}\text { Arthroscopically } \\
\text { assisted fixation (K wire } \\
\text { (three cases), } \\
\text { cancellous screw (two } \\
\text { cases), } 5.5 \mathrm{~mm} \text { suture } \\
\text { anchor utilized in each } \\
\text { case (one case), } \\
\text { followed by WBAT x } \\
\text { four weeks followed by } \\
\text { PT). }\end{array}$ & $\begin{array}{l}\text { All >2 cm, edema } \\
\text { around the lesser } \\
\text { trochanter with a } \\
\text { capsular injury and } \\
\text { partial tear of the } \\
\text { iliopsoas. No } \\
\text { heterotrophic } \\
\text { ossification around } \\
\text { the fragment. }\end{array}$ & Full recovery & $\begin{array}{l}\text { Allowed to } \\
\text { return } 10- \\
12 \text { weeks } \\
\text { post-op. } \\
\text { Patients } \\
\text { with acute } \\
\text { injuries } \\
\text { returned to } \\
\text { impact } \\
\text { activity. }\end{array}$ & $\begin{array}{l}\text { One case of } \\
\text { numbness on the } \\
\text { medial side of } \\
\text { the knee (anterior } \\
\text { femoral } \\
\text { cutaneous nerve } \\
\text { of the thigh), } \\
\text { resolved two } \\
\text { weeks after } \\
\text { surgery }\end{array}$ \\
\hline $\begin{array}{l}\text { Vazquez et } \\
\text { al. [9] }\end{array}$ & 1 & 15 & $\begin{array}{l}\text { Non-operative (NWB } \\
\text { with crutches, analgesic, } \\
\text { a gradual return to } \\
\text { activity at six weeks) }\end{array}$ & Not reported & Full recovery & $\begin{array}{l}\text { Not } \\
\text { reported }\end{array}$ & None reported \\
\hline Fasting [21] & 1 & 13 & $\begin{array}{l}\text { Open reduction/fixation } \\
\text { (wire), followed by six } \\
\text { weeks NWB in a spica } \\
\text { cast }\end{array}$ & ot reported & $\begin{array}{l}\text { Full recovery, full bony } \\
\text { union at two-year follow-up }\end{array}$ & Yes & None reported \\
\hline $\begin{array}{l}\text { Theologis } \\
\text { et al. [10] }\end{array}$ & 3 & $\begin{array}{l}(1.2 \\
5.3 \\
8.8)\end{array}$ & $\begin{array}{l}\text { Non-operative (one was } \\
\text { treated with hip spica, } \\
\text { two with bed rest and } \\
\text { crutches) }\end{array}$ & lot reported & $\begin{array}{l}\text { Full recovery in all cases. } \\
\text { Case } 3 \text { injured lateral thigh } \\
\text { three years after a fracture, } \\
\text { radiographs showed fibrous } \\
\text { union with the lesser } \\
\text { trochanter prox. Cases } 1 \\
\text { and } 2 \text { were asymptomatic at } \\
\text { seven and nine-year follow } \\
\text { up. }\end{array}$ & Yes $(3 / 3)$ & None \\
\hline $\begin{array}{l}\text { Papacostos } \\
\text { et al. [15] }\end{array}$ & 1 & 15 & $\begin{array}{l}\text { Non-operative, period of } \\
\text { non-weight bearing and } \\
\text { PT }\end{array}$ & Not reported & Full recovery & Yes & None \\
\hline $\begin{array}{l}\text { Obi et al. } \\
\text { [22] }\end{array}$ & $\begin{array}{l}1 \text { (bilateral } \\
\text { injuries on } \\
\text { separate } \\
\text { occasions) }\end{array}$ & 15 & $\begin{array}{l}\text { Non-operative } \\
\text { (analgesia, WBAT with } \\
\text { crutches with full } \\
\text { weight-bearing at six } \\
\text { weeks. Sport restricted } \\
\text { for three months) }\end{array}$ & Not reported & $\begin{array}{l}\text { Full recovery, asymptomatic } \\
\text { within six weeks. Bilateral } \\
\text { solid bony union at six- } \\
\text { month follow-up. }\end{array}$ & $\begin{array}{l}\text { Yes, three } \\
\text { months }\end{array}$ & None \\
\hline $\begin{array}{l}\text { McMillan et } \\
\text { al. [23] }\end{array}$ & $\begin{array}{l}1 \text { (bilateral } \\
\text { injuries } \\
\text { following } \\
\text { separate } \\
\text { seizures) }\end{array}$ & 16 & $\begin{array}{l}\text { Non-operative (rest, } \\
\text { analgesia, WBAT, PT) }\end{array}$ & Not reported & $\begin{array}{l}\text { Full recovery of both hips } \\
\text { (seen at } 12 \text { months post- } \\
\text { injury). No pain or functional } \\
\text { defect. }\end{array}$ & Yes & None \\
\hline
\end{tabular}

TABLE 3: Summary of case reports on lesser trochanter avulsion fractures 
All patients were successfully managed nonoperatively with no additional sequelae or treatments. All 30 patients involved in sports returned to the sport after non-operative treatment for approximately one month, resulting in an average return to sport in less than three months. Ruffing et al. recently published a case series of successful non-operative treatment of lesser trochanter avulsion injuries that resulted in a $100 \%$ return to sport rate. However this study had a sample size of 5 , so the potential application of these findings is limited [20]. Eberbach et al. published a systematic review of operative versus nonoperative management in all apophyseal avulsion fractures of the pelvis [24]. Of the 596 patients included, approximately $10(1.8 \%)$ had lesser trochanter avulsion fractures. Although the injury locations were not specified in the treatment intervention, the authors reported that patients had better overall outcome scores following surgical intervention, especially in those patients with fracture displacement greater than $15 \mathrm{~mm}$. They also noted similar complication rates between the two groups, however, this was generalized between all pelvic avulsion injuries [11,24-26].

Metzmaker and Pappas published the first large series of general pelvic avulsion injuries treated nonoperatively in a specific five-phase rehabilitation protocol, lasting 60 days minimum [7]. Only three patients of the 27 had lesser trochanter avulsion injuries. Twenty-four of the 27 (88\%) had a full return to sport. One of those patients had a lesser trochanter avulsion re-injury for returning to sport too early and had a delayed return to full activity. Eberbach et al. argued this treatment protocol of at least 60 days was too long a period of convalescence and would adversely disrupt regular training and fitness in young athletes. However, a return to sport too early can lead to re-injury of a lesser trochanter avulsion and overall delayed recovery as shown by Metzmaker and Pappas [7,24].

The results that are shown by Metzmaker and Pappas coincide with our retrospective review in which all patients returned to sports at an average of 78 days after nonoperative treatment in a specific rehabilitation protocol. However, in the present study, over half of the patients were allowed to be weight-bearing as tolerated at the initiation of treatment. In addition, formal physical therapy was only prescribed in 18 of 30 cases.

There are also reports in the literature regarding operative indications for pelvic avulsion injuries and guarded results in nonoperative treatment $[2,8,10,17]$. Although there are limited publications regarding the operative treatment of lesser trochanter avulsion injuries, Khemka et al. reported a case series of arthroscopically-assisted open reduction internal fixation of lesser trochanter avulsion injuries with cannulated screws in three patients with no complications [17]. Reported indications in the literature for surgical intervention of adolescent avulsion fractures include displacement of $>2 \mathrm{~cm}$, painful nonunion, exostosis, and inability to return to sport [17,27-32]. The concerns addressed by Khemka et al. regarding displaced lesser trochanter avulsion fractures were non-union and loss of strength secondary to muscle shortening. In their series of three patients, all of the patients had lesser trochanter avulsion fractures greater than $2 \mathrm{~cm}$. In addition to the concerns listed above, Khemka et al. additionally noted ischiofemoral impingement (IFI) as a potential consideration when treating lesser trochanter avulsion fractures conservatively. IFI was first described in 1977 by Johnson, noting impingement symptoms when the distance between the lesser trochanter and ischium decreased, from a displaced fracture [17,33-35]. Khemka expanded on this by reporting the incidence of IFI may increase in lesser trochanter avulsion fractures displaced greater than $2 \mathrm{~cm}$ and with associated heterotopic ossification [17]. However, this article did not address the potentially greater risk of IFI that screw fixation can create by decreasing the size of the lesser trochantericischial space. This potential risk should be seriously considered and addressed when discussing treatment options with patients and their families. Surgical intervention may also increase the risk of heterotopic ossification, as reported following both open and arthroscopic hip procedures, further increasing the risk of IFI [36-38].

However, Khemka et al. concluded that arthroscopically assisted fixation of displaced lesser trochanter fractures helps to minimize chances of non-union, loss of muscle strength, and potentially IFI [17]. Moreover, this study did not define what a "chronic" versus "acute" lesser trochanter avulsion fracture was defined as, and it does not appear that any healing time was allowed prior to moving forward with the surgical intervention. In the literature, lesser avulsion fractures have been grouped into the classification system used for all other avulsion fractures [1]. Reports of nonunion due to ischial tuberosity fractures leading to IFI have been published and used as an indication for surgical intervention [39]. However, to the best of our knowledge, there have not been any reports of non-unions in lesser trochanter avulsions in the literature or within the limited follow-up of our own case series. Therefore, performing surgery in order to prevent nonunion fractures as they describe does not appear to be a valid indication for surgery moving forward.

Regarding return to sport, their results are very similar to our study. Their three patients underwent a postoperative protocol of weight-bearing as tolerated with crutches for four weeks, with a return to sport at 1012 weeks. This parallels our study showing 30 patients, treated conservatively for approximately four weeks and an average return to sport at 11 weeks. The key takeaway from the results of our study is that equivalent time to return to normal function and sport can be achieved using conservative treatment, therefore, avoiding the surgical risks and economic burden related to undergoing a procedure.

This study has several limitations. First, it is retrospective in nature. A prospective, randomized trial would 
yield the most precise analysis of treatment protocols; however, this may be difficult given the relatively uncommon nature of this injury. Second, only certain aspects of treatment were able to be analyzed, for example, duration of treatment and time of return to sport. We were unable to procure data such as hip range of motion, strength testing, or functional and sports-specific outcome scores. This was likely due to the retrospective nature of the study, and the variety of providers that the patients in this study were treated by. Pediatric orthopedic surgeons, pediatric sports medicine orthopedists, primary care sports medicine physicians, and general pediatricians all treated the patients included in this study, hence, the differing weight-bearing status and rehabilitation protocols.

Additional future directions include investigating the potential long-term effects of this injury, such as the development of IFI, as well as looking at potential predisposing factors of avulsion fractures such as lesser trochanter version. Schroder et al. have shown the lesser trochanter version to have a moderate correlation with the femoral version, supporting the finding that patients with increased femoral neck version are at higher risk for extra-articular impingement at the lesser trochanter and ischial tuberosity $[40,41]$.

In summary, this retrospective case series demonstrates one of the largest cohorts of adolescent patients sustaining avulsion fractures of the lesser trochanter, with full return to sport in under three months' time after undergoing nonoperative management. This study highlights that most patients were allowed to weight-bear as tolerated, and formal physical therapy was only required in eighteen of thirty patients. These data show that adolescent patients sustaining avulsion injuries of the lesser trochanter can reliably return to sport without surgical intervention, be allowed to weight bear as tolerated, and do not necessarily need formal physical therapy. Although this retrospective study demonstrates excellent results with nonoperative management, prospective, randomized studies and assessment of functional and sports-specific outcome scores would further guide treatment strategies.

\section{Conclusions}

Lesser trochanter avulsion injuries in adolescent athletes can be treated conservatively with an average return to normal function and sports time of less than three months. This is the first large case series studying avulsion injuries of the lesser trochanter. We have shown that these athletes can be managed nonsurgically and can successfully return back to sport within three months.

\section{Additional Information \\ Disclosures}

Human subjects: Consent was obtained or waived by all participants in this study. Northwell Institutional Research Board issued approval IRB \#: 17-0708. Our study was approved by the Northwell IRB for our institution Northwell Lenox Hill to conduct our retrospective chart review study. Animal subjects: All authors have confirmed that this study did not involve animal subjects or tissue. Conflicts of interest: In compliance with the ICMJE uniform disclosure form, all authors declare the following: Payment/services info: All authors have declared that no financial support was received from any organization for the submitted work. Financial relationships: All authors have declared that they have no financial relationships at present or within the previous three years with any organizations that might have an interest in the submitted work. Other relationships: Srino Bharam, Consultant for Smith and Nephew Endoscopy.

\section{References}

1. McKinney BI, Nelson C, Carrion W: Apophyseal avulsion fractures of the hip and pelvis . Orthopedics. 2009, 32:42. 10.3928/01477447-20090101-12

2. Fernbach SK, Wilkinson RH: Avulsion injuries of the pelvis and proximal femur. AJR Am J Roentgenol. 1981, 137:581-4. 10.2214/ajr.137.3.581

3. Amaral JF: Thoracoabdominal injuries in the athlete. Clin Sports Med. 1997, 16:739-53. 10.1016/s02785919(05)70051-X

4. Suarez JC, Ely EE, Mutnal AB, Figueroa NM, Klika AK, Patel PD, Barsoum WK: Comprehensive approach to the evaluation of groin pain. J Am Acad Orthop Surg. 2013, 21:558-70. 10.5435/JAAOS-21-09-558

5. Paletta GA, Andrish JT: Injuries about the hip and pelvis in the young athlete . Clin Sports Med. 1995, 14:591-628. 10.1016/S0278-5919(20)30209-X

6. Rossi F, Dragoni S: Acute avulsion fractures of the pelvis in adolescent competitive athletes: prevalence, location and sports distribution of 203 cases collected. Skeletal Radiol. 2001, 30:127-31. $10.1007 / \mathrm{s} 002560000319$

7. Metzmaker JN, Pappas AM: Avulsion fractures of the pelvis . Am J Sports Med. 1985, 13:349-58. $10.1177 / 036354658501300510$

8. Dimon J: Isolated fractures of the lesser trochanter of the femur . Clin Orthop Relat Res. 1972, 15:144-8.

9. Vazquez E, Kim TY, Young TP: Avulsion fracture of the lesser trochanter: an unusual cause of hip pain in an adolescent. Can J Emerg Med. 2013, 15:124-6. 10.2310/8000.2012.120613

10. Theologis TN, Epps H, Latz K, Cole WG: Isolated fractures of the lesser trochanter in children . Injury. 1997, 28:363-64. 10.1016/s0020-1383(97)00017-X

11. Ferlic PW, Sadoghi P, Singer G, Kraus T, Eberl R: Treatment for ischial tuberosity avulsion fractures in adolescent athletes. Knee Surg Sports Traumatol Arthrosc. 2014, 22:893-7. 10.1007/s00167-013-2570-4 
12. Orava S, Ala-Ketola L: Avulsion fractures in athletes. Br J Sports Med. 1977, 11:65-71. 10.1136/bjsm.11.2.65

13. Sundar M, Carty H: Avulsion fractures of the pelvis in children: a report of 32 fractures and their outcome . Skeletal Radiol. 1994, 23:85-90. 10.1007/BF00563198

14. Ganz R, Slongo T, Turchetto L, Massè A, Whitehead D, Leunig M: The lesser trochanter as a cause of hip impingement: pathophysiology and treatment options. Hip Int. 2013, 23 Suppl 9:S35-41. 10.5301/hipint.5000063

15. Papacostas NC, Bowe CT, Shaffer Strout TD: Lesser trochanter avulsion fracture. J Emerg Med. 2013, 45:2567. 10.1016/j.jemermed.2013.01.021

16. Li X, Xu S, Lin X, Wang Q, Pan J: Results of operative treatment of avulsion fractures of the iliac crest apophysis in adolescents. Injury. 2014, 45:721-4. 10.1016/j.injury.2013.10.005

17. Khemka A, Raz G, Bosley B, Ludger G, Al Muderis M: Arthroscopically assisted fixation of the lesser trochanter fracture: a case series. J Hip Preserv Surg. 2014, 1:27-32. 10.1093/jhps/hnu006

18. Pisacano RM, Miller TT: Comparing sonography with MR imaging of apophyseal injuries of the pelvis in four boys. AJR Am J Roentgenol. 2003, 181:223-30. 10.2214/ajr.181.1.1810223

19. Torode I, Zieg D: Pelvic fractures in children. J Pediatr Orthop. 1985, 5:76-84. 10.1097/01241398198501000-00014

20. Ruffing T, Rückauer T, Bludau F, Hofmann A, Muhm M, Suda AJ: Avulsion fracture of the lesser trochanter in adolescents. Injury. 2018, 49:1278-1281. 10.1016/j.injury.2018.04.030

21. Fasting OJ: Avulsion of the less trochanter. Arch Orthop Trauma Surg. 1978, 91:81-3. 10.1007/BF00383646

22. Obi NJ, Allman C, Moore-Thompson E, Latimer MD: Sequential bilateral lesser trochanter avulsion fractures in an adolescent patient. BMJ Case Rep. 2014, 2014:207911. 10.1136/bcr-2014-207911

23. McMillan T, Rehman H, Mitchell M: Lesser trochanter avulsion fracture in an adolescent after seizure . J Emerg Med. 2016, 51:457-60. 10.1016/j.jemermed.2016.06.007

24. Eberbach H, Hohloch L, Feucht MJ, Konstantinidis L, Südkamp NP, Zwingmann J: Operative versus conservative treatment of apophyseal avulsion fractures of the pelvis in the adolescents: a systematical review with meta-analysis of clinical outcome and return to sports. BMC Musculoskelet Disord. 2017, 18:162. 10.1186/s12891-017-1527-z

25. Gottsegen CJ, Eyer BA, White EA, Learch TJ, Forrester D: Avulsion fractures of the knee: imaging findings and clinical significance. Radiographics. 2008, 28:1755-70. 10.1148/rg.286085503

26. Schuett DJ, Bomar JD, Pennock AT: Pelvic apophyseal avulsion fractures: a retrospective review of 228 cases . J Pediatr Orthop. 2015, 35:617-23. 10.1097/BPO.0000000000000328

27. Mbubaegbu CE, O'Doherty D, Shenolikar A: Traumatic apophyseal avulsion of the greater trochanter: case report and review of the literature. Injury. 1998, 29:647-9. 10.1016/S0020-1383(98)00152-1

28. Rajasekhar C, Kumar KS, Bhamra MS: Avulsion fractures of the anterior inferior iliac spine: the case for surgical intervention. Int Orthop. 2001, 24:364-5. 10.1007/s002640000184

29. Saluan P, Weiker G: Avulsion of the anterior inferior iliac spine . Orthopedics. 1997, 20:558-9.

30. Kosanović M, Brilej D, Komadina R, Buhanec B, Pilih IA, Vlaović M: Operative treatment of avulsion fractures of the anterior superior iliac spine according to the tension band principle. Arch Orthop Trauma Surg. 2002, 122:421-3. 10.1007/s00402-002-0396-5

31. Pointinger H, Munk P, Poeschl GP: Avulsion fracture of the anterior superior iliac spine following apophysitis. Br J Sports Med. 2003, 37:361-2. 10.1136/bjsm.37.4.361

32. Howard F: Fractures of the apophyses in adolescent athletes . JAMA J Am Med Assoc. 1965, 192:842. 10.1001/jama.1965.03080230048012

33. Stafford GH, Villar RN: Ischiofemoral impingement. J Bone Joint Surg Br. 2011, 93:1300-2. 10.1302/0301620X.93B10.26714

34. Lee S, Kim I, Lee SM, Lee J: Ischiofemoral impingement syndrome. Ann Rehabil Med. 2013, 37:143-6. 10.5535/arm.2013.37.1.143

35. Taneja AK, Bredella MA, Torriani M: Ischiofemoral impingement. Magn Reson Imaging Clin N Am. 2013, 21:65-73. 10.1016/j.mric.2012.08.005

36. Bedi A, Zbeda R, Bueno V, et al.: The incidence of heterotopic ossification after hip arthroscopy . Am J Sports Med. 2012, 40:854-63. 10.1177/0363546511434285

37. Amar E, Sharfman Z, Rath E: Heterotopic ossification after hip arthroscopy. J Hip Preserv Surg. 2015, 2:255263. 10.1093/jhps/hnv052

38. Byrd J: Special patients and conditions: other forms of impingement (ishiofemoral, pectineofoveal) . Hip Joint Restoration. McCarthy J, Noble P, Villar R (ed): Springer, New York; 2017. 203-9.

39. Spencer-Gardner L, Bedi A, Stuart MJ, Larson CM, Kelly BT, Krych AJ: Ischiofemoral impingement and hamstring dysfunction as a potential pain generator after ischial tuberosity apophyseal fracture nonunion/malunion. Knee Surg Sports Traumatol Arthrosc. 2017, 25:55-61. 10.1007/s00167-015-3812-4

40. Schröder RG, Reddy M, Hatem MA, Gómez-Hoyos J, Toye L, Khoury A, Martin HD: A MRI study of the lesser trochanteric version and its relationship to proximal femoral osseous anatomy. J Hip Preserv Surg. 2015, 2:410-6. 10.1093/jhps/hnv067

41. Siebenrock K, Steppacher S, Haefeli P, et al.: Valgus hip with high anteversion cause pain through posterior extraarticular FAI. Clin Orthop Relat Res. 2013, 471:3774-80. 10.1007/s11999-013-2895-9 